\title{
Compreender é transgredir
}

\section{RESUMO}

Desvendando pistas para uma arqueologia da compreensão, o artigo problematiza as interconexões entre comunicação e compreensão, a partir da assertiva de Edgar Morin de que a comunicação não garante a compreensão.

\section{PALAVRAS-CHAVE}

- compreensão

- comunicação

- mundialização

\section{ABSTRACT}

Triying to unveil tracks to an archaeology of comprehension, this article renders problematic interconnections between communication and understanding, from Edgar Morin's assertive that communication does not guarantee comprehension.

\section{KEY WORDS}

- comprehension

- communication

- globalization

\section{Margarida Maria Knobbe UFRN}

$\mathbf{N}$ os seis volumes de $\mathbf{0}$ Método, Edgar Morin me faz estranhar e, ao mesmo tempo, me reconhecer como indivíduo integrante de uma sociedade e pertencente à espécie humana. Estranho e reconheço também os outros pela mesma relação indivíduo/sociedade/espécie. Cada um de nós é único e vários ao mesmo tempo.

A despeito de nossas inúmeras potencialidades, nos comportamos, às vezes, como máquinas triviais, repetindo-nos incessantemente. Talvez seja essa uma imposição da cultura e do pacto social. Como náufragos que remam, remam, remam mesmo sabendo que continuarão à deriva, sem rumo. Porém, na realidade, somos máquinas não triviais, por dispor de uma possibilidade de afastamento em relação à norma, de um potencial de catálise, de descoberta, de decisão (MORIN, 2002, p. 281).

Toda essa riqueza do antropos vêm à tona pela via da comunicação, na maioria das vezes, de uma forma sutilmente implícita. A comunicação, por sua vez, se constitui num fluir de coordenações consensuais de ações, no dizer de Humberto Maturana. Para haver comunicação, nesse sentido mais amplo e fundamental, é necessário que haja proximidade física ou noológica entre os interlocutores. Essa proximidade responde à aptidão humana ao duplo, a objetivar-se, reconhecerse a si mesmo como um outro (Paul Ricoeur), mecanismos que Edgar Morin denomina de identificação/ projeção.

Identificação e projeção são mecanismos contrários e complementares ao mesmo tempo. O outro participa na construção da minha identidade, porque, ao vê-lo, vejo que é o mesmo: serve-me, então, de espelho, argumenta o etólogo Boris Cyrulnik (s/d, p. 175).

Esses mesmos mecanismos necessários à comunicação estão presentes nos processos de compreensão. Para Morin, a compreensão é um modo fundamental de conhecimento antropossocial, que comporta a projeção (de si sobre o outro) e a identificação (de outro consigo), realizando um duplo movimento que se refere à distinção do eu e do outro, mesmo em conjunção (1996, p. 139).

Se são assim tão imbricados os fenômenos da comunicação e da compreensão, por que o primeiro não garante a efetivação do segundo? Talvez porque, mesmo sendo necessário para a minha existência, assim que aparece no meu campo de consciência, o outro altera o meu mundo. Um paradoxo assim descrito por Cyrulnik: assim que me sinto observado por outro inquieto-me. A consciência do outro em mim agride-me. A ausência do outro em mim faz-me morrer. Quando estou só, o mundo pertence-me, mas morro. Quando aparece outro no meu mundo, agride-me e permite-me viver (s/d, p. 183).

A comunicação com o outro-mesmo raramente gera compreensão. E os conflitos se acentuam com os altos 
índices de ansiedade provocados pelas contingências psíquicas e sociais. Por exemplo, cita Cyrulnik, para os animais dominados, tal como para os seres humanos deprimidos, o encontro não é um enriquecimento, mas sim uma agressão. No entanto, ainda argumenta o etólogo, de todos os organismos, o ser humano é, provavelmente, o mais dotado para a comunicação porosa (física, sensorial e verbal), que estrutura o vazio entre dois parcei$\operatorname{ros}(\mathrm{s} / \mathrm{d}, \mathrm{p} .185)$.

\section{Vivemos permanentemente estressados pelo excesso, pelas dificuldades de opção, em pânico por termos que tomar decisões.}

De outra parte, as formas de comunicação que herdamos do século XX nos afastaram tanto da base física quanto da base noológica, primárias, das coordenações consensuais de ação. Os vazios se acumulam. Há um silêncio em meio a todo barulho. Um silêncio que não se classifica como $o$ intervalo preciso para as modulações da comunicação, a respiração de sentido (LE BRETON, 1997, p. 75). Não é uma fuga de palavras, é o dito da recusa. A escuta desse silêncio não contém a presença do outro. O que conterá? Resistência? Rancor? Desprezo? Controle?

Talvez pela recusa do outro e pela destruição do sentido, a linguagem tenha se tornado caduca. Apenas o som inteligível das palavras reveste o vazio que persegue o silêncio. As palavras pronunciadas não esconjuram esse silêncio, não preenchem o abismo de sentido. É assim porque adotamos as couraças dos mídia, a sua impessoalidade, até na convivência familiar.

É possível observar na vida cotidiana alguns traços comportamentais que refletem a ascendência que as máquinas inteligentes - o computador, a TV e outras caixas pretas - exercem sobre nós, forçando-nos ao silêncio. Nas palavras do filósofo Jean-Michel Besnier:

uma concepção do mundo é igualmente feita de atitudes estabelecidas como uma segunda natureza: por exemplo, suportamos cada vez menos a ambigüidade nas relações humanas, preferindo, em seu lugar, uma linguagem simplificada (...) Não é verdade que a informática convivial ou mesmo os sistemas especializados nos prometem uma comunicação sem esforço nem ironia, sem profundidade nem mal-entendidos? (2001, p. 159)
Não é igualmente sintomático o fato de que, em meio a todo processo de mundialização, inclusive dos meios de comunicação, se amplifique o mal primordial da incompreensão humana? (MORIN, 2003, p. 363). Contra as recusas e o silêncio que copulam com os aspectos perversos, bárbaros e viciosos do ser humano, consubstanciados nas incompreensões, ambições, sede de lucro, poderes e explorações que habitam o nosso mundo, Morin propõe uma reforma do pensamento, mas também uma reforma do ser humano mesmo. Tal metamorfose supõe uma reforma radical dos sistemas de educação, que supõe uma grande corrente de compreensão... (Id., p. 365).

A palavra compreensão, contudo, já está presente como operadora de conhecimento em qualquer proposta ou nível escolar. É palavra-chave em toda investigação científica. Compreender, afirma-se, é um dos objetivos da ciência, especialmente das ciências ditas humanas, embora muitas vezes seus resultados sejam apenas tentativas de explicação. Às vezes, dissociando meios e fins, criamos técnicas (meios) para explicar o que pretendemos compreender (fim).

As técnicas por si mesmas não explicam ou fazem compreender. Nem a ciência. Nem a arte. Há sempre um ou mais sujeitos cognoscentes por trás e à frente desses processos. Penso na técnica/arte do cinema, por exemplo. Mais especificamente, penso em Charles Chaplin e em sua capacidade de compreensão do que ocorria no mundo para criar o filme $O$ grande ditador, em 1940, época na qual muitos governos, inclusive o dos Estados Unidos, eram complacentes e, digamos, se faziam de inocentes em relação ao perigo que Adolf Hitler representava para a humanidade. Por que Chaplin atingiu tal compreensão enquanto a maioria da população mundial, mesmo aqueles que possuíam informações privilegiadas sobre os acontecimentos, precisaram assistir às cenas do genocídio como fato consumado, anos depois, para acionar os seus mecanismos da compreensão?

No roteiro da comédia dramática de Chaplin, produzido em 1939, enquanto a Alemanha nazista invadia a Polônia, nos primeiros passos da Segunda Guerra Mundial, o grande ditador Hynkel possui todo o globo terrestre, brinca e dança com ele até explodi-lo.

Ainda hoje permanece atual a fala do personagem barbeiro judeu: Mais que máquinas, precisamos de humanidade (...) Pensamos demais e sentimos pouco.

O que é, então, compreender? É pensar? É sentir?

Diz Morin que tanto a superioridade quanto a inferioridade dos humanos é ter sentimentos, que podem ser loucos. Os sentimentos devem mesmo ser importantes nos processos de compreensão/incompreensão, mas será que são suficientes para deflagrá-los, para explicá-los e para compreendê-los?

Morin também afirma que os poderes da compreensão são insuficientes para compreender a própria compreensão. Para isso, a compreensão deve combinar-se por um lado com processos de verificação (em 
relação aos riscos de erro e de incompreensão), por outro lado com processos de explicação:

Enquanto compreender é captar as significações existenciais de uma situação ou de um fenômeno, explicar é situar um objeto ou um acontecimento em relação à sua origem ou modo de produção, às suas partes ou componentes constitutivas, à sua constituição, às suas utilidades, à sua finalidade; é situá-lo numa causalidade determinista e numa ordem corrente (1996, p. 140).

\section{Tentar compreender algo apenas pelo viés da razão conduz a um estado de inércia, à indiferença.}

Há uma dialógica entre compreensão e explicação. Para Morin, a compreensão se refere aos aspectos do pensamento simbólico/mitológico/mágico: concreto, analógico, captações globais, predominância da conjunção, projeções/identificações, implicação do sujeito, pleno emprego da subjetividade. E a explicação está ligada às características do pensamento empírico/lógico/racional: abstrato, lógico, captações analíticas, predominância da disjunção, demonstrações, objetividade, dessubjetivização. Mesmo sendo necessária à compreensão, a explicação pode traí-la e gerar incompreensão, porque seus princípios da objetivação, determinação e racionalidade estão sujeitos às cristalizações e erros da racionalização, quando se julga que tudo é explicado ou explicável por uma visão de mundo ou uma teoria.

Além da dialogia entre o pensamento mito-lógico, que abarca a recursividade dos processos de explicação e compreensão, viver é conhecer, segundo o biólogo Henri Atlan. Essa concepção baseia-se na premissa de Humberto Maturana de que os sistemas vivos são sistemas cognitivos, independentemente da existência de um sistema nervoso nos organismos. Ainda de acordo com Atlan, as propriedades de conhecimento, de consciência e de compreensão emergiram das organizações celulares. Não são atribuídos, porém, às células isoladas, mas emergem a partir de interações entre as células, sobretudo os neurônios que podem se auto-organizar e apresentar propriedades cognitivas, mesmo que nenhum destes neurônios conheça, nem compreenda o que quer que seja (ATLAN, 2003, p. 256).

Nem no âmbito individual nem no âmbito social um termo pode ser reduzido ao outro. Considerando a comunicação social, também não devemos confundir comunicação e compreensão. A comunicação, lembra Morin, é comunicação de informação às pessoas ou grupos que podem entender o que significa a informação
(2002, p. 42-43). Mas a compreensão é um fenômeno que mobiliza poderes subjetivos para considerar o outro também como sujeito. Multiplicamos as formas de comunicação no planeta e não conseguimos compreender próximos e distantes.

Tendo por base as concepções de Morin, Maturana e Atlan, considero que, apesar de terem nascido no mesmo berço, conhecer não é compreender. Conhecer é tratar informações; compreender é assumir para si e incorporar o conhecimento. Também suponho que os processos comunicativos em nossa sociedade têm distanciado cada vez mais a comunicação da compreensão.

Sem pretender atingir toda a verdade, mimetizome no pretume molar dos antigos ajuntamentos de gente, hoje em extinção, e me transporto para dentro das desprezadas massas coloridas e moleculares de Peter Sloterdijk. A massa somos todos nós, analfabetos e intelectuais, ricos e pobres, homens e mulheres que pactuam com o permutável e com a indiferença. Falta-nos, como sugere Emile Cioran, exercícios de admiração (apud SLOTERDIJK, 2002, p. 116).

Quantas vezes nos escondemos sob o espectro do coletivo para justificar um certo desespero embaçado pelo desprezo a nós mesmos? Somos incapazes do esforço para admirar em um dos nossos pares, principalmente no âmbito profissional e intelectual, valores, talentos e obras que nós mesmos não somos capazes de produzir, mesmo que tivéssemos trinta e seis vidas (Id., p. 117).

Vivemos permanentemente estressados pelo excesso, pelas dificuldades de opção, em pânico por termos que tomar decisões. Ao mesmo tempo, cultuamos celebridades vazias. Exilamos os sujeitos de suas obras e de suas idéias. E aderimos ao discurso da moda que prega a diversidade, desde que haja consenso do coletivo sobre qual diversidade podemos tolerar. Cada um opta conforme seu capricho, sua ilusão, sua miopia, mas responsabiliza a coletividade por suas opções.

Essa propalada diversidade é o túmulo da diferença e da compreensão. Seja qual for o grupo de referência, ser massa significa diferenciar-se sem que se faça nenhuma diferença. Indiferença diferenciada é o mistério formal da massa e sua cultura, que organiza um centro total. Por essa razão, seu jargão não pode ser outro senão o de um individualismo afiado (Id., p. 107).

A massa compromete a todos no mesmo fracasso. Mata toda tentativa individual de fazer-melhor-doque-os-outros. Segundo Sloterdijk, nessas condições o reconhecimento não pode mais significar alta estima ou homenagem, mas baixa estima ou igual estima no espaço neutro, justa concessão de uma insignificância que não se contesta de ninguém (Id.).

A que triste fim estamos empurrando antigos ideais democráticos... ao parlamento das ficções, que 
antes a sociologia chamava de opinião pública. Não querendo participar das unanimidades, paradoxalmente, criamos o humano homogêneo, para suspeitar contra tudo o que é criativo e livre.

O termo barbárie me parece aqui justificado. É o que George Steiner chama de um mundo absolutamente chato, no qual tudo se equivale e nada vale nada (apud MATTÉI, 2002, p. 259). É o que mostra, com um humor fino e sutil, o romance Como me tornei estúpido (2005), do antropólogo Martin Page, que constata: A inteligência torna a pessoa infeliz, solitária, pobre, enquanto o disfarce de inteligente oferece a imortalidade efêmera (p. 7).

Tentando salvar-se, Antoine, o protagonista da história, tenta renunciar ao pensamento criador porque tinha poucos amigos, porque padecia dessa espécie de antisociabilidade que resulta da demasiada tolerância e compreensão. Depois de tentativas mal-sucedidas para embriagar-se e suicidar-se, empreende uma jornada rumo à estupidez, argumentando que, na natureza, tudo o que vive muito e contente não é inteligente. Com os humanos, em nosso mundo, tentar compreender é um suicídio social.

Bem antes de Page, outros escritores já se dedicaram ao tema, provando que a arte é sempre contemporânea e real, como afirma Dostoievski. O próprio escritor russo publicou em 1868 a história O idiota, na qual o quixotesco príncipe Michkin, acometido de epilepsia, vai a fundo em todas as questões de que trata quando começa a falar, demonstrando uma profunda compaixão humanista por todos os indivíduos.

\section{É do seu próprio lugar de observador, com seus determinismos e contingências, que cada um pode chegar a uma compreensão ou objetivação entre parênteses.}

Akira Kurosawa adaptou a narrativa para o cinema em $1951^{1}$. No filme, Kenji Kameda, um ex-militar japonês que escapou da morte, passa a sofrer de idiotice - amor incondicional à vida e às pessoas. A doença o enreda numa tragédia. O problema maior de Kameda é a sua incapacidade de distinguir e optar pelo bem ou pelo mal. Enxergando no olhar do outro todo o sofrimento de sua humanidade, o idiota Kameda confunde amor com pena. A empatia incondicional acaba causando mais sofrimento. Assim, a compreensão extrema de Kameda se torna incompreensão, com o uso inconseqüente do livre arbítrio. No desenrolar das cenas, a maldade acaba assumindo uma valoração positiva porque permite o exercício da liberdade de escolha.
Se, para Dostoievski e Kurosawa, a compreensão se refere à empatia que imobiliza a capacidade de julgamento, portanto, se consuma na doença da idiotia, para Page, a estupidez - renúncia à compreensão promove uma falsa felicidade. A idiotia poderia ser chamada de hipercompreensão e a estupidez, de hipocompreensão. Idiotia e estupidez são como duas doenças que causam sérios prejuízos à saúde social. São contrários extremos que aniquilam - por excesso ou por falta - a verdadeira compreensão que exige novas emergências de idéias e atitudes.

Porém, compreensão é outra palavra polissêmica por natureza. Como reconhecer suas múltiplas faces?

O filósofo-médico Álcmeon de Crotona (século V) afirma que o homem difere dos outros animais porque somente ele tem a capacidade de compreensão, enquanto as outras criaturas têm apenas sensações. Para o escoliasta Virgílio, cansamo-nos de tudo, exceto de compreender. Mas, na verdade, mesmo que não compreendamos nada, pontifica o poeta Fernando Pessoa:

A ânsia de compreender, que para tantas almas nobres substitui a de agir, pertence à esfera da sensibilidade. Substituir a inteligência à energia, quebrar o elo entre a vontade e a emoção, despindo de interesse todos os gestos da vida material, eis o que, conseguido, vale mais que a vida, tão difícil de possuir completa, e tão triste de possuir parcial (1996, p. 243).

A compreensão pertence à esfera da sensibilidade e da ação porque o pensamento também cansa, de acordo com o poeta. Tentar compreender algo apenas pelo viés da razão conduz a um estado de inércia, à indiferença. Por outro lado, não cansamos de tentar compreender porque é dessa forma que, ao esgotarmos os próprios pensamentos, temos necessidade de sentir o influxo das opiniões alheias, mesmo que não sigamos o seu impulso.

Por sua vez, Diógenes, filósofo cínico (404-323 a. C.), ao tratar dos sentidos, destaca o sensor do paladar - a língua, como um meio privilegiado para obter informações (sintomas) e compreender o prazer e a dor, a saúde e a doença. Há também quem afirme que uma das manifestações táteis, o arrepio, sinaliza a conquista da compreensão. O eriçamento da pele significaria, assim, a informação de que a ação pretendida ou realizada, a sensação, percepção ou entendimento alcançados são confiáveis e merecem validação.

Os sentidos, até hoje, são utilizados para compreender, por exemplo, o vinho. Na técnica da degustação dos sommeliers, usa-se o termo compreender como resultado dos exames visual, olfativo e gustativo, sem dispensar a tatilidade e a audição do líquido escorrendo na taça. Infinitas combinações emergem desse processo, assim descrito por Enrico Bernardo:

A degustação me abriu as portas do prazer e da análise científica. Após anos de aprendizagem, sempre em busca do saber mais exato, misturan- 
do profundamente a volúpia da degustação à experiência, descobri quanto uma garrafa pode ser a síntese de um perfeito equilíbrio entre a natureza, a mão do homem, as tecnologias e a história vinícola. A degustação não é outra coisa senão a expressão desse conhecimento criador de harmonia (2006, p. 20).

Ou seja, a compreensão é um conhecimento criador de harmonia, situado às portas do prazer e da análise científica.

A história da palavra compreensão é longa e polifônica. Hans-Georg Gadamer atribui ao termo alemão Verstehen o significado original de compreender (1998, p. 394, nota 174). Verstehen, no sentido jurídico, quer dizer representar uma causa perante um tribunal; causa essa que necessita ser compreendida, ou dominada, até o ponto em que se possa fazer frente a toda possível objeção da parte contrária.

A compreensão, assim, é encarada como auto-sócio-conhecimento e pressupõe a partilha do sentimento de verdade. A linguagem é o meio no qual se realiza o acordo dos interlocutores para o entendimento da causa.

Martin Heidegger, ainda segundo Gadamer, utiliza o termo compreender como tomar posição a favor de...: Nesse sentido, vale para todos os casos que aquele que compreende se compreende, projeta a si mesmo rumo a possibilidades de si mesmo (p. 394). Hermann Hesse parece concordar com essa assertiva quando diz: Ninguém pode ver nem compreender nos outros o que ele próprio não tiver vivido. Nessa concepção, há congruência de padrões de experiência; há acoplamento.

A concepção jurídica, contudo, não encontra eco em outros autores. André Malraux, por exemplo, afirma: Se compreendêssemos nunca mais poderíamos julgar. Isso porque participamos juntos de um mesmo sentido. Já Baruch Spinoza, praticamente higieniza o que quer que seja compreender das emoções: Não rir, nem lamentar-se, nem odiar, mas compreender. E Jean Piaget atribui à compreensão o segundo estágio do conhecimento, que ocorre quando o indivíduo se apropria da informação para, em seguida, engajar-se num comprometimento (1977).

Gadamer, anti-dogmaticamente, em sua hermenêutica filosófica não busca as causas, mas a história efeitual do que se quer compreender. Entende a compreensão como um processo ativo, de confronto e resposta, mediatizado através de uma estrutura complexa. Portanto, para ele não basta encarar o compreender como um método. Muito mais que isso, o compreender é o modo pelo qual temos acesso à realidade social. E - concordando com Piaget - a compreensão da realidade social exige comprometimento.

Dessa forma, o funcionamento último de toda compreensão terá que ser sempre um ato adivinhatório de congenialidade, cuja possibilidade repousará sobre a vinculação prévia de todas as individualidades. Em última instância, compreender é recriar e comprome- ter-se. Portanto, pressupõe o sujeito criador plenamente inserido em sua condição unitas multiplex ${ }^{2}$.

Essa recriação, de acordo com Humberto Maturana, sempre está condicionada ao padrão de cada sujeito. É do seu próprio lugar de observador, com seus determinismos e contingências, que cada um pode chegar a uma compreensão ou objetivação entre parênteses. Essas contingências não são apenas individuais; são também culturais. Um exemplo: o cineasta espanhol Carlos Saura ${ }^{3}$ conta que, na época da ditadura franquista em seu país, ia assistir na França aos filmes - proibidos na Espanha - de seu compatriota Luis Buñuel. Em uma dessas vezes, na exibição de $E l^{4}$, apenas Saura e mais uns dois ou três espectadores riram durante a sessão. Ao final, Saura percebeu que aqueles que manifestaram ter compreendido o humor de Buñuel eram todos espanhóis. Os franceses, por sua vez, experimentaram, segundo Saura, uma compreensão pela via do silêncio e da seriedade em respeito ao cineasta que admiravam.

Mesmo que os padrões de cada sujeito fujam da repetição em direção a bifurcações, variâncias, conforme aposta Ilya Prigogine, a compreensão, ainda assim, será entre parênteses porque diz respeito àquele sujeito. Como afirma um antigo adágio, um leopardo nunca pode mudar as suas pintas...

\section{No filme Babel, a decomposição das relações familiares e a hierarquia de cidadania se projetam sobre as solidões individuais que formam nichos culturais.}

Apesar do meu universo de pertencimentos, acredito que a compreensão é um desafio que minha mente pode e deve ultrapassar em algumas questões pontuais, através de um diálogo constante com as próprias mutações que consigo identificar em meus padrões de pensamento. Isso significa não estar à procura de soluções, mas de interrogações, principalmente dado que não há solução definitiva se encaramos o pensamento como um sistema aberto.

Talvez seja o que Heidegger chama de aletheia, entendida como desvelamento, diferentemente da verdade do pensamento, que traduz como certeza. Em suas próprias palavras: A aletheia é o impensado digno de ser pensado, é o objeto por excelência do pensamento (apud STEIN, 2001, p. 57). Nesse sentido, a compreensão pode ser a própria memória do ser que compreende, porque carrega toda a história dos avanços e retrocessos do seu aprendizado, do seu conhecimento, num movimento recursivo. 
Ou, como quer David Bohm, a compreensão é parte de um fluxo universal de onde podem ser abstraídos inúmeros padrões. Quando diferentes fatores se ajustam e se relacionam como aspectos de uma totalidade, acontece um lampejo de compreensão, proporcionado por atos de percepção (1992, p. 34). É o que acontece tanto nos insights científicos como nos artísticos. Num lampejo de compreensão, por exemplo, Newton elaborou a teoria da gravitação universal: assim como a maçã cai, o mesmo acontece com a lua e, de fato, com todas as coisas. Em outras palavras: compreender é descobrir o imensurável através do impensado digno de ser pensado. Disso se compreende que toda compreensão é fugaz.

\section{A metáfora bíblica da torre de Babel sintetiza essa impossibilidade da compreensão absoluta.}

A compreensão pode também ser vista como uma bissociação, segundo termo utilizado por Arthur Koestler para designar o ato de criação. Essa bissociação, Koestler localiza no humor, nas ciências e nas artes, e diz respeito à produção de novos insights, além do contrabando de idéias e sentidos, como no processo metafórico (apud SWANWICH, 2003).

E é a metáfora, para Keith Swanwich, que permite melhor compreender. Para ela, a metaphorá - que significa transporte de um lugar para outro - é um fenômeno dinâmico configurado pela interseção de dois ou mais domínios, que nos permite ver as coisas diferentemente, para pensar novas coisas. Swanwich não se refere apenas à metáfora lingüística. A autora defende a tese de que a metáfora é um processo genérico fundamental, inclusive quando a música informa a vida do sentimento. Em seu livro Ensinando música, musicalmente, ela identifica a metáfora com a música, como um elemento de novidade que surge das relações potencialmente dissonantes (Id., p. 25).

Essa novidade, diz o neurocientista Itzhak Fried, responde à capacidade mental do humano em direção a outra perspectiva. Fried localiza no humor a viagem exploratória e criativa da compreensão. Segundo a teoria da incongruência, o humor se baseia na percepção de uma incoerência, de um paradoxo, frente ao qual o cérebro abandona todas as expectativas e passa a perseguir novas idéias. Ocorre, então, uma mudança de perspectiva. Passando de uma solução logicamente antecipada a um cenário desconcertante, rimos porque descobrimos que esse novo não é ruim nem uma ameaça ${ }^{5}$.

O riso liberta o pensamento lógico. Ele nos desarma, inclusive no sentido biológico, porque rompe a reação de lutar ou fugir (herança animal impressa em nosso cérebro triúnico ${ }^{6}$ ), que situações ameaçadoras deflagram, fazendo cair o nível de adrenalina e reduzindo a tensão. Num sentido contrário, a angústia é a compreensão do nada.

A metáfora e o riso são brechas abertas - ou quebras de padrões - na lógica dedutivo-identitária, que possibilitam a compreensão. Ou seja, compreender é transgredir. Da mesma forma que, para a escritora Lya Luft, refletir é transgredir a ordem do superficial. Ainda segundo ela, amadurecer serve para isso: o novo olhar, na lucidez de certo distanciamento, permite compreender aspectos nossos e alheios antes obscuros. Por vezes promove-se uma espécie de anistia. Partindo dela podem-se reconfigurar padrões $(2004$, p. 68,153$)$.

A reconfiguração de padrões, em termos individuais e sociais, também lembra a letra da música Da lama ao caos, de Chico Science: desorganizando posso organizar; me organizando posso desorganizar...

Transgredir, amadurecer, anistiar, desorganizar/ organizar são termos que evocam um sujeito autor de si mesmo, que está em processo, em viagem, em curso. Em viagem significa estar em constante construção e desconstrução da própria identidade, confrontandoa com as alteridades. Assim como a identidade, a compreensão também se constrói por complementaridade, como sugere Teresa Vergani: todo o sistema de compreensão é um sistema de intercompreensão alicerçado na reciprocidade das diferenças (1995, p. 29). Qualquer ato de compreensão é, igualmente, uma escolha, consciente ou não. Um ato de liberdade axiomática, radicalmente oposto a qualquer processo de dogmatização.

Não há apenas uma compreensão válida acerca de um fato, de um fenômeno, de um processo. Portanto, a compreensão é sempre construída a partir da escolha de um ou mais princípios existentes num universo de diversidade de princípios. A compreensão, então, é sempre relativa, e se justifica pela autenticidade do relativismo assumido no momento de se decidir a escolha. Ou, como já cantou o compositor Lobão, a compreensão é a maravilhosa precariedade na permanência ${ }^{7}$.

Por outro lado, quando o sentimento de certeza ser arvora à condição absoluta - o que não é nada raro ocorrer, pois a certeza dá prazer -, a compreensão se torna loucura. A certeza enlouquece: se afoga narciso! ${ }^{8}$

Como mostra esse rápido panorama, embora seja utilizado como sinônimo de diversos processos sensoriais e cognitivos, como informar, conhecer, explicar, interpretar etc., o próprio sentido do compreender ultrapassa todos os termos.

Comungo da idéia de Gilles Deleuze e de Félix Guattari (1992) de que todo conceito, toda noção se esvanece, adquire novos componentes, se reordena. Por isso não há um conceito único que se amolde a uma única coisa. Toda noção possui um contorno irregular, heterogêneo, e sempre remete a outros conceitos em seu devir. Além disso, o pensamento científico, por mais que tentemos limitá-lo a uma rígida 
configuração, se entrelaça, sem operar uma síntese, às proposições e às percepções da filosofia e da arte.

A palavra compreensão, como tantas outras dos vocabulários de todos os idiomas, serve também para manipulações dissimuladas da linguagem. George Orwell, em seu profético livro 1984, nos alerta contra o totalitarismo da novilingua, criada pelos poderes para nos obrigar a pensar como eles. Cabe a cada um de nós o esforço de, frente a cada discurso que prega e fala de compreensão, perguntar sobre a ideologia camuflada nas palavras.

Assim, toda compreensão é uma viagem sem fim: chega a alguns portos, se reabastece e volta a partir. Toda compreensão é pontual, parcial, provisória, lacunar e inacabada.

Etimologicamente, compreender, nas suas raízes latinas, é formada pela junção do prefixo com mais o verbo prehender ou praehendere, formando comprehendere ou compraehendere, que significa:

1. com as mãos agarrar, prender, tomar ou apoderarse de, pegar;

2. apanhar em flagrante, surpreender;

3. então tomar conjuntamente, pelo todo, abrangentemente; ainda atar juntamente, ligando;

4. tomar pela raiz, na base;

5. conceber um bebê (dar à luz, sacar, ter um insight).

No idioma inglês, compreender completamente ou corretamente (to comprehend completely or correctly) é realizar - to realize -, concretizar, perceber, dar-se conta: to make real; to convert from the imaginary or fictitious into the actual; to bring into concrete existence.

Todas essas significações corroboram as características elencadas por Morin sobre o processo da compreensão - que se refere aos aspectos do pensamento simbólico/mitológico/mágico: concreto, analógico, captações globais, predominância da conjunção, projeções/identificações, implicação do sujeito, pleno emprego da subjetividade. A etimologia também confirma as diferenças entre compreender e explicar. Explicação é formada pelo prefixo ex, com idéia de saída, de conclusão, acabamento, mais o verbo plicare que quer dizer dobrar, enroscar, formando explicatio, que pode ser entendido como:

1. ação de desdobrar, desenrolar, estender, desenfardar;

2. esclarecimento e interpretação;

3. expor pormenorizadamente, narrando;

4. desembaraçar, livrar, acabar, terminar, concluir. (BRAGAMICH, 2003)
Em inglês, explicar - to explain - também se refere a justificar, ilustrar, motivar e fundamentar. Tomando por base essas significações, considero, como David Bohm, que, ao reforçar continuamente o hábito fragmentário de pensar, acabamos tomando o conteúdo do nosso pensamento por uma descrição do mundo como ele é. Ora reduzimos a compreensão à explicação; ora estabelecemos que uma compreensão dá conta de toda a complexidade da realidade. Porém, na maioria das vezes, a compreensão é unicamente uma teoria, uma forma de insight (ou introvisão), ou seja, um modo de olhar para o mundo, e não uma forma de conhecimento de como ele é. Por outro lado, não há nenhuma razão para supor que existe ou existirá uma forma de insight final (correspondente à verdade absoluta), ou mesmo uma série uniforme de aproximações dessa forma final (BOHM, 1992, p. 22, 24).

A metáfora bíblica da torre de Babel sintetiza essa impossibilidade da compreensão absoluta. Porém, não são os diferentes idiomas que mais atrapalham a comunicação entre os seres humanos. Nem tanto a ausência de algum sentido, como a audição ou a fala ${ }^{9}$. As muralhas intransponíveis são as emoções e as questões culturais, sociais e políticas. Atualizando o mito bíblico, o filme Babel (2006), do mexicano Alejandro González Iñárritu, mostra como essas muralhas se fortaleceram no planeta mundializado. Um labirinto de histórias conecta pessoas que vivem no Marrocos, nos Estados Unidos, no México e no Japão. $\mathrm{O}$ enredo $^{10}$ compõe-se de pequenos atos que se transformam em grandes tragédias, numa demonstração inequívoca da ecologia da ação, sugerida por Morin: toda ação escapa, cada vez mais, à vontade do seu autor na medida em que entra no jogo das inter-retro-ações do meio onde intervém (2005, p. 41). E é esse jogo do qual todos fazemos parte, mesmo sem consciência do nosso papel de jogadores, que compromete qualquer tentativa de chegarmos às formas absolutas de compreensão e de comunicação.

\section{Não são os diferentes idiomas que mais atrapalham a comunicação entre os seres humanos.}

No filme Babel, a decomposição das relações familiares e a hierarquia de cidadania (os norte-americanos são tratados como se fossem mais cidadãos do que os habitantes de outros países) se projetam sobre as solidões individuais que formam nichos culturais, sociais e políticos de coletivos magoados que, por sua vez, transformam as vidas cotidianas em apocalipse. Não há compreensão quando a turista norte-americana precisa de atendimento médico no interior do Marro- 
cos. O governo de seu país, inferindo ter sido ela vítima de um ato terrorista, não permite o envio de uma ambulância marroquina. Não há compreensão quando a babá mexicana precisa cruzar a fronteira com as crianças norte-americanas, para levá-las de volta para casa. Não há compreensão quando os meninos marroquinos tentam explicar à polícia de seu país que não são terroristas. Não há compreensão quando a japonesa surda-muda tenta demonstrar que tudo o que quer é ser aceita como é e amada.

Apesar da incomunicação verbal, são possíveis alguns tênues entendimentos: uma idosa marroquina acalma a dor da norte-americana ferida; a jovem japonesa surda-muda demonstra toda a sua vulnerabilidade a um estranho; as crianças norte-americanas sabem o que a babá mexicana lhes diz em espanhol.

Dessa forma, Iñárritu destrói a babel das línguas e constrói outra, a de um mundo absurdo - porém real onde reina o desamor, como se repetisse os versos de Renato Russo sobre poema de Luís de Camões: Ainda que eu falasse a lingua dos homens. E falasse a lingua dos anjos, sem amor eu nada seria ${ }^{11}$. Ou, posso acrescentar: sem amor eu nada compreenderia... Mas como causar pode seu favor nos corações humanos amizade, se tão contrário a si é o mesmo amor? afamecos

\section{NOTAS}

\section{Filme Hakushi, o idiota.}

2. Como Morin designa a unidade genérica, unidade complexa ou unidade múltipla humana e a tríade complexa indivíduo-sociedade-espécie. Unidade que gera a multiplicidade que regenera novamente a unidade.

3. Em entrevista ao canal de TV Globonews, em janeiro de 2006.

4. Produzido em 1952, o filme é um estudo do comportamento paranóico de uma pessoa neurótica e autoritária. Consta que Jacques Lacan teria confessado haver utilizado as situações vividas pelo personagem em suas aulas de psiquiatria (In: www. luisbunuel.org).

5. Gelontologia - estudo do riso. Viver Mente \& Cérebro - Revista de Psicologia, Psicanálise, Neurociências e Conhecimento - Ano XIII - n. 141, out./ 2004, p. 34-39.

6. A partir das pesquisas de Mac Lean, Edgar Morin elabora a versão complexa do cérebro triúnico: uma unitas multiplex cerebral humana de uma herança animal ultrapassada, mas não abolida; uma trindade, e não uma tripartição, que comporta o paleocéfalo reptiliano; o mesocéfalo dos antigos mamíferos, e o córtex que, no homem, alcança um desenvolvimento extraordinário com o neocórtex (MORIN, 1996, p. 90).

7. Música Samba da caixa preta.

8. Idem.

9. Para Boris Cyrulnik, a linguagem é o sexto sentido humano.

10. Um caçador japonês oferece a espingarda ao seu guia marroquino, que a vende a um pastor. Esse, por sua vez, a dá aos filhos para protegerem os rebanhos dos chacais. Os meninos entretêm-se a disparar contra um ônibus de turismo e atingem uma norte-americana, em viagem de reconciliação com o marido. Os filhos do casal estão aos cuidados de uma empregada mexicana, imigrante ilegal. Sem ter com quem deixá-los, atravessa com eles a fronteira, para assistir ao casamento do filho. No regresso, conduzidos pelo sobrinho da mexicana, têm problemas com a polícia fronteiriça e as crianças acabam perdidas no deserto. A mexicana é extraditada. O caçador japonês, cuja esposa suicidou-se, tem uma filha surda-muda que tenta integrar-se aos grupos jovens de Tóquio, freqüentando bares e boates e fazendo uso de drogas.

11. Letra da música Monte Castelo.

\section{REFERÊNCIAS}

ATLAN, Henri. Vida, conhecimento e ética. In: Polifônicas idéias - por uma ciência aberta. Orgs. ALMEIDA, M. C.; KNOBBE, M. M.; ALMEIDA, A. Porto Alegre: Sulina, 2003.

BERNARDO, Enrico. Aprender a gostar de vinho pelo melhor sommelier do mundo. Trad. Luís Horta. São Paulo: Editora Nacional, 2006.

BESNIER, Jean-Michel. A inteligência artificial nos torna superficiais? In: PESSIS-PASTERNAK, Guitta. A ciência: deus ou diabo? São Paulo: Editora UNESP, 2001.

BOHM, David. A totalidade e a ordem implicada. Trad. Mauro de Campos Silva. SP: Cultrix, 1992.

BRAGAMICH, Rubens. Digressões acerca da idéia de compreensão. Texto apresentado na seção Temas Livres do XI Simpósio Internacional da Associação Junguiana do Brasil, realizado em 2003.

CYRULNIK, Boris. Memória de macaco e palavras de homem. Trad. Ana Maria Rabaça. Lisboa: Instituto Piaget, s/d. 
DELEUZE, Gilles; GUATTARI, Félix. O que é a filosofia? Trad. Bento Prado Jr. E Alberto Alonso Muñoz. Rio de Janeiro: 34, 1992.

DOSTOIEVSKI, Fiodor. O idiota. Trad. Paulo Bezerra. Rio de Janeiro: 34, 2002.

GADAMER, Hans-Georg. Verdade e Método - traços fundamentais de uma hermenêutica filosófica. Trad. Flávio Paulo Meurer; revisão da tradução de Ênio Paulo Giachini. Petrópolis/RJ: Vozes, 1998, 2a . ed.

LE BRETON, David. Do silêncio. Trad. Luís M. Couceiro F. Lisboa: Instituto Piaget, 1997.

LUFT, Lya. Perdas e ganhos. Rio de Janeiro: Record, $26^{a}$. ed., 2004.

MATTÉI, Jean-François. A barbárie interior - ensaio sobre o i-mundo moderno. Trad. Isabel Maria Loureiro. São Paulo: Editora UNESP, 2002.

MATURANA, Humberto R.; VARELA, Francisco J. A árvore do conhecimento: as bases biológicas da compreensão humana. Trad. Humberto Mariotti e Lia Diskin. São Paulo: Palas Athena, 2001.

MORIN, Edgar. O Método III - O conhecimento do conhecimento. Portugal: Publicações EuropaAmérica, 1996.

—. O método 5 - a humanidade da humanidade: a identidade humana. Trad. Juremir Machado da Silva. Porto Alegre: Sulina, 2002.

—. Uma mundialização plural. In: Por uma outra comunicação - mídia, mundialização cultural e poder. Org. Denis de Moraes. Rio de Janeiro: Record, 2003.

—_. O método 6 - ética. Trad. Juremir Machado da Silva. Porto Alegre: Sulina, 2005.

ORWELL, George. 1984. Trad. Wilson Velloso. São Paulo: Companhia Editora Nacional, 1984, $17^{\mathrm{a}}$. Ed.

PAGE, Martin. Como me tornei estúpido. Trad. Carlos Nougué. Rio de Janeiro: Rocco, 2005.

PESSOA, Fernando. Livro do Desassossego, vol. I. Campinas, SP: Editora da Unicamp, 1996.

PIAGET, Jean. O desenvolvimento do pensamento. Equilibração das Estruturas Cognitivas.
Lisboa: Dom Quixote, 1977.

PRIGOGINE, Ilya e STENGERS, Isabelle. A nova aliança-metamorfose da ciência. Trad. Miguel Faria e Maria Joaquina Machado Trincheira. Brasília: Ed. UnB, 1997.

STEIN, Ernildo. Compreensão e finitude: estrutura e movimento da interrogação heideggeriana. Ijuí: Ed. Unijuí, 2001.

SLOTERDIJK, Peter. O desprezo das massas - ensaio sobre lutas culturais na sociedade moderna. Trad. Claudia Cavalcanti. São Paulo: Estação Liberdade, 2002.

SWANWICH, Keith. Ensinando música, musicalmente. São Paulo: Ed. Moderna, 2003.

VERGANI, Teresa. Excrementos do sol - a propósito de diversidades culturais. Lisboa: Pandora, 1995. 